\title{
Is there a relationship between renal scarring and neutrophil-to-lymphocyte ratio in patients with vesicoureteral reflux?
}

\author{
Mehmet Demir, İsmail Yağmur, Eyyup Sabri Pelit, Bülent Katı, Eser Ördek, Halil Çiftçi \\ Department of Urology, Harran University, Sanliurfa, Turkey.
}

\begin{abstract}
Summary Objectives: Vesicoureteral reflux (VUR) exacerbates the risk of renal scarring by establishing a ground for pyelonephritis. It is known that the inflammatory process is more influential than the direct damage caused by bacterial infection in the development of renal scars after pyelonephritis. Therefore, the present study aims to investigate the relationship between renal scarring and systemic inflammatory markers in patients with VUR.

Material and methods: Hundred and ninety-two patients (116 females, 76 males) diagnosed with VUR were divided into two groups based on the presence or absence of renal scarring and into three groups according to the grade of VUR (low, moderate and high). Neutrophil count, lymphocyte count, mean platelet volume (MPV) and neutrophil-to-lymphocyte ratio (NLR) were compared among the groups.

Results: Of the 192 patients, 102 had renal scarring. The age and gender distribution did not differ significantly between the groups with and without renal scarring $(p>0.05)$. However, the grade of reflux and lymphocyte count were significantly higher in the group with renal scarring $(p<0.05)$, and the NLR was significantly lower in the group with renal scarring $(p<0.05)$. The lymphocyte count was significantly higher $(p<0.05)$ and NLR was significantly lower in the high-grade VUR group $(p<0.05)$. However, MPV values did not differ significantly $(p>0.05)$ between the groups.

Conclusions: NLR can be used to predict renal scarring in patients with VUR, especially in the period of 3-6 months after the first attack of infection, and may even serve as a candidate marker for treatment selection. However, larger series and prospective studies are needed.
\end{abstract}

KEY WORDS: Vesicoureteral reflux; Neutrophil-to-lymphocyte ratio; Pyelonephritis; Renal scarring.

Submitted 15 October 2021; Accepted 28 October 2021

\section{INTRODUCTION}

Vesicoureteral reflux (VUR) is a functional and anatomical disorder that can result in renal scarring, hypertension and end-stage renal failure (1). VUR predisposes the patients to urinary tract infection (UTI) and pyelonephritis and increases the risk of scarring in the kidney (2). Renal scarring is an important cause of hypertension and chronic renal failure (CRF) in children and young adults (3). The etiopathogenesis of renal scarring has not been clearly understood. However, lymphocytes play an important role in the initi- ation of renal fibrosis (4). The infiltrating lymphocytes, monocytes/macrophages and mast cells activate and produce reactive oxygen species (ROS) after infection and release fibrogenic cytokines and growth factors $(5,6)$. The resulting damage causes interstitial inflammation, collagen deposition and disruption of the normal tubular arrangement. As a result, permanent parenchymal damage and scar formation occur, which are accompanied by tubular atrophy and interstitial fibrosis (7). Even if the infection is treated and VUR is corrected, the inflammatory process continues and scars may, therefore, develop (1).

It is known that the complete blood count parameters vary qualitatively and quantitatively in inflammatory processes (8) and that the neutrophil-to-lymphocyte ratio (NLR) is effective in predicting inflammation (9). Platelets also contribute to increased inflammation by enhancing the secretion of cytokines at the beginning of inflammation (10). Mean thrombocyte volume (MPV) level can be used as an indicator of platelet functions (11).

Tc-99m dimercaptosuccinic acid (DMSA) scintigraphy is the gold standard in detecting the development of renal scars after pyelonephritis (12). Pyelonephritic inflammatory changes in the kidney occur immediately and can be detected with DMSA. While some of these acute changes resolve within 6 months, some lead to renal scarring (13). Currently, the development of scars in patients cannot be predicted as there is no easily accessible predictive marker for renal scar development. If such a marker is identified, improvements can be made in the follow-up and treatment algorithm of patients with VUR.

The present study aims to compare the NLR and MPV values in patients having VUR with and without renal scarring. To the best of our knowledge, this is the first study on the topic.

\section{MATERIALS AND METHODS}

The hospital records of patients diagnosed with VUR using voiding cystourethrography (VCUG) between January 2008 and August 2020 were retrospectively reviewed. Ethics committee approval was granted by our Faculty Ethics Committee (HRU/16.06.27). Patients' age, frequency of past UTI episodes, use of prophylactic antibiotics, physical examination findings, blood urea nitrogen and creatinine, complete blood count, complete urinalysis, 
urine culture, ultrasound (USG), VCUG and DMSA findings were examined. The VCUG findings of the patients were evaluated according to the standards of the International Reflux Study in Children (14). Most of the patients were admitted to our clinic with the pre-diagnosis of VUR after acute infection, for further investigation, some of them were diagnosed with VUR after acute infection and for follow-up and treatment, and some of them were directly admitted to our clinic because of recurrent UTI. No new VCUG was performed in patients diagnosed with VUR and referred to our clinic. Imaging was performed in our hospital for patients who were referred with a pre-diagnosis of VUR and did not have VCUG. DMSA scintigraphs, provided that they were performed 3-6 months after the occurrence of UTI, were examined. DMSA scintigraphies taken during the acute infection period were not included in the study.

The renal parenchymal scar was defined as cortical thinning, volume loss, decreased DMSA uptake and renal contour irregularities. Neutrophil count, lymphocyte count and MPV values were recorded by examining the results of complete blood count at the time of DMSA acquisition, and it was established that the patients had no active infection by demonstrating a sterile urine culture. Patients with malignant diseases and those on chronic anti-inflammatory drug therapy were excluded from the study. Patients with secondary VUR caused by other factors, such as neurogenic bladder and posterior urethral valve, and those with voiding dysfunction were excluded from the study. Hundred and ninety-two patients with accessible data were included in the study. The patients were divided into two groups based on the presence or absence of renal scarring and into three groups according to the grade of VUR (mild: grades I-II, moderate: grade III; high: grades IV-V). Neutrophil count, lymphocyte count, MPV values and NLR were compared among the groups.

\section{Statistical methods}

Mean, standard deviation, median, minimum, maximum value frequency and percentage were used for descriptive statistics. Kolmogorov-Smirnov test was employed to check the distribution of the variables. Mann-Whitney $\mathrm{U}$ test was used for the comparison of the quantitative data. Chi-square test was used for the comparison of the qualitative data. SPSS 26.0 was used for the statistical analysis.

\section{RESULTS}

Of the 192 patients with VUR, 116 were females, and 76 were males. The mean age of the patients was $5.4 \pm 5$ years. Of the patients, 124 had unilateral and 68 had bilateral VUR (Table 1).

The age and gender distribution did not differ significantly between patients with and without renal scarring $(p>0.05)$. The rates of renal scarring were $9 \%, 32.5 \%$, $57.1 \%, 67.3 \%$ and $65.6 \%$ in patients with grade I, II, III, IV and V VUR, respectively. The VUR grade and lymphocyte counts were significantly higher $(p<0.05)$ and the neutrophil count and NLR were significantly lower $(\mathrm{p}<$ 0.05) in the group with renal scarring than in the group without renal scarring. The MPV values did not differ sig-
Table 1.

Demographic data of the patients.

\begin{tabular}{|ll|c|c|cc|}
\hline & & Min-max & Median & \multicolumn{2}{c|}{ Mean $\pm \mathbf{s d} / \mathbf{n}-\%$} \\
\hline Age & $0.10-36.00$ & 4.00 & $5.40 \pm 5.00$ \\
\hline Gender & Girl & & & 116 & $60.4 \%$ \\
& Boy & & & $76 \quad 39.6 \%$ \\
\hline Side & Right & & & 43 & $22.4 \%$ \\
& Left & & & 81 & $42.2 \%$ \\
& Bilateral & & & 68 & $35.4 \%$ \\
\hline Grade & I & & & 11 & $5.7 \%$ \\
& II & & & 40 & $20.8 \%$ \\
& III & & & 63 & $32.8 \%$ \\
& IV & & & 36 & $24.0 \%$ \\
& V & $1.10-10.80$ & 4.70 & $4.78 \pm 1.89$ \\
\hline Neutrophil & $1.30-9.90$ & 3.70 & $4.07 \pm 1.55$ \\
\hline Lymphocyte & $0.20-4.06$ & 1.22 & $1.37 \pm 0.79$ \\
\hline NLR & $4.20-10.70$ & 6.20 & $6.36 \pm 0.99$ \\
\hline MPV & & & \\
\hline NLR: Neutrophil Lymphocyte Ratio; MPV: Mean Platelet Volume. & & \\
\hline
\end{tabular}

Table 2.

Comparison of patients with and without renal scarring.

\begin{tabular}{|c|c|c|c|c|c|c|c|c|}
\hline & & Mean & $\begin{array}{r}S c a r( \\
\pm \mathrm{sd} / \mathrm{n}-\%\end{array}$ & Median & Mean & $\begin{array}{r}S c a r(+ \\
\pm \mathrm{sd} / \mathrm{n}-\%\end{array}$ & Median & $P$ \\
\hline$\overline{\text { Age }}$ & & 5.80 & \pm 6.36 & 4.00 & 5.04 & \pm 3.37 & 4.00 & $0.620 \mathrm{~m}$ \\
\hline$\overline{\text { Gender }}$ & $\begin{array}{l}\text { Girl } \\
\text { Boy }\end{array}$ & $\begin{array}{l}54 \\
36\end{array}$ & $\begin{array}{l}60.0 \% \\
40.0 \%\end{array}$ & & $\begin{array}{c}62 \\
40\end{array}$ & $\begin{array}{l}60.8 \% \\
39.2 \%\end{array}$ & & $0.912 x^{2}$ \\
\hline Side & $\begin{array}{l}\text { Right } \\
\text { Left } \\
\text { Bilateral }\end{array}$ & $\begin{array}{l}19 \\
42 \\
29\end{array}$ & $\begin{array}{l}21.1 \% \\
46.7 \% \\
32.2 \%\end{array}$ & & $\begin{array}{l}24 \\
39 \\
39\end{array}$ & $\begin{array}{l}23.5 \% \\
38.2 \% \\
38.2 \%\end{array}$ & & $0.492 x^{x^{2}}$ \\
\hline$\overline{\text { Grade }}$ & $\begin{array}{l} \\
\text { II } \\
\text { III } \\
\text { IV } \\
\text { V }\end{array}$ & $\begin{array}{l}10 \\
27 \\
27 \\
15 \\
11\end{array}$ & $\begin{array}{l}11.1 \% \\
30.0 \% \\
30.0 \% \\
16.7 \%\end{array}$ & & $\begin{array}{c}1 \\
13 \\
36 \\
31 \\
21\end{array}$ & $\begin{array}{c}1.0 \% \\
12.7 \% \\
35.3 \% \\
30.4 \% \\
20.6 \%\end{array}$ & & $0.000 \mathrm{~K}^{2}$ \\
\hline$\overline{\text { Neutrophil }}$ & & 5.19 & \pm 1.70 & 4.90 & 4.42 & \pm 1.98 & 4.40 & $0.002 \mathrm{~m}$ \\
\hline Lymphocyt & & 3.71 & \pm 1.25 & 3.60 & 4.39 & \pm 1.71 & 3.80 & $0.020^{\mathrm{m}}$ \\
\hline$\overline{\mathrm{NLR}}$ & & 1.59 & \pm 0.83 & 1.38 & 1.16 & \pm 0.70 & 0.99 & $0.000 \mathrm{~m}$ \\
\hline$\overline{\mathrm{MPV}}$ & & 6.28 & \pm 0.92 & 6.10 & 6.43 & \pm 1.04 & 6.30 & $0.395 \mathrm{~m}$ \\
\hline
\end{tabular}

nificantly ( $p>0.05)$ between the groups with and without renal scarring (Table 2).

According to the grade of reflux, the patients were divided into three groups, that is, low (grades I-II), intermediate (grade III) and high (grades IV-V) VUR groups. Lymphocyte count was significantly higher in the highgrade VUR group than in the low- and moderate-VUR groups ( $p<0.05)$. NLR was significantly lower in the high-grade VUR group than in the low- and moderateVUR groups $(p<0.05)$. However, neutrophil count and MPV values did not differ significantly according to the grade of VUR ( $p>0.05)$ (Table 3$)$.

In the sub-data analysis, the patients who were divided into three groups (low, moderate and high) according to the degree of reflux were further divided into two groups based on the presence or absence of renal scarring. The neutrophil count was significantly lower in scar-positive patients with low-grade (grades I-II) VUR $(p<0.05)$ than in scar-negative patients. However, lymphocyte count and NLR did not differ significantly ( $p>0.05$ ) (Table 4). 
Table 3.

Comparison of patients according to the grade of reflux.

\begin{tabular}{|c|c|c|c|c|c|c|c|c|c|c|c|}
\hline \multirow[b]{2}{*}{ Age } & & \multicolumn{3}{|c|}{$\begin{array}{c}\text { Grade I-II } \\
\text { Mean } \pm \mathrm{sd} / \mathrm{n}-\% \quad \text { Median }\end{array}$} & \multicolumn{3}{|c|}{$\begin{array}{c}\text { Grade III } \\
\text { Mean } \pm \mathbf{s d} / \mathrm{n}-\% \quad \text { Median }\end{array}$} & \multicolumn{3}{|c|}{$\begin{array}{c}\text { Grade IV-V } \\
\text { Mean } \pm \mathrm{sd} / \mathrm{n}-\% \quad \text { Median }\end{array}$} & \multirow{2}{*}{$\begin{array}{c}P \\
0.005^{K}\end{array}$} \\
\hline & & 7.50 & \pm 7.14 & 7.00 & 5.14 & \pm 3.71 & 5.00 & 4.23 & \pm 3.67 & 4.00 & \\
\hline Gender & $\begin{array}{l}\text { Girl } \\
\text { Boy }\end{array}$ & $\begin{array}{l}40 \\
11\end{array}$ & $\begin{array}{l}78.4 \% \\
21.6 \%\end{array}$ & & $\begin{array}{l}39 \\
24\end{array}$ & $\begin{array}{l}61.9 \% \\
38.1 \%\end{array}$ & & $\begin{array}{l}37 \\
41\end{array}$ & $\begin{array}{l}47.4 \% \\
52.6 \%\end{array}$ & & $0.002^{X^{2}}$ \\
\hline Side & $\begin{array}{l}\text { Right } \\
\text { Left } \\
\text { Bilateral }\end{array}$ & $\begin{array}{l}12 \\
28 \\
11\end{array}$ & $\begin{array}{l}23.5 \% \\
54.9 \% \\
21.6 \%\end{array}$ & & $\begin{array}{l}15 \\
25 \\
23\end{array}$ & $\begin{array}{l}23.8 \% \\
39.7 \% \\
36.5 \%\end{array}$ & & $\begin{array}{l}16 \\
28 \\
34\end{array}$ & $\begin{array}{l}20.5 \% \\
35.9 \% \\
43.6 \%\end{array}$ & & $0.124^{X^{2}}$ \\
\hline Neutrophil & & 4.79 & \pm 1.93 & 4.50 & 5.05 & \pm 1.75 & 5.10 & 4.56 & \pm 1.95 & 4.45 & $0.146^{K}$ \\
\hline Lymphocyte & & 3.51 & \pm 1.13 & 3.10 & 3.95 & \pm 1.50 & 3.60 & 4.55 & \pm 1.69 & 4.20 & $0.001^{K}$ \\
\hline$\overline{N L R}$ & & 1.51 & \pm 0.78 & 1.28 & 1.51 & \pm 0.84 & 1.45 & 1.16 & \pm 0.72 & 1.01 & $0.004^{K}$ \\
\hline$\overline{\mathrm{MPV}}$ & & 6.23 & \pm 0.90 & 6.10 & 6.41 & \pm 0.99 & 6.30 & 6.40 & \pm 1.04 & 6.15 & $0.540^{k}$ \\
\hline
\end{tabular}

\section{Table 4.}

Comparison of patients with and without renal scarring according to the grade of reflux.

\begin{tabular}{|c|c|c|c|c|c|c|c|c|}
\hline & & Mean & $\begin{aligned} & \text { Scar (-) } \\
\pm & \text { sd } / \mathrm{n}-\%\end{aligned}$ & Median & Mean & $\begin{array}{r}\text { Scar }(+ \\
1 \pm \mathrm{sd} / \mathrm{n}-\%\end{array}$ & Median & P \\
\hline \multirow{4}{*}{$\overline{\text { Grade I-II }}$} & Neutrophil & 4.95 & \pm 1.55 & 4.80 & 4.38 & \pm 2.73 & 3.30 & $0.038^{\mathrm{m}}$ \\
\hline & Lymphocyte & 3.59 & \pm 1.25 & 3.30 & 3.28 & \pm 0.71 & 3.10 & $0.619 \mathrm{~m}$ \\
\hline & NLR & 1.53 & \pm 0.66 & 1.41 & 1.45 & \pm 1.05 & 0.97 & $0.202^{m}$ \\
\hline & MPV & 6.19 & \pm 0.89 & 6.10 & 6.36 & \pm 0.94 & 6.40 & $0.398 \mathrm{~m}$ \\
\hline \multirow[t]{4}{*}{ Grade III } & Neutrophil & 5.39 & \pm 1.49 & 5.20 & \begin{tabular}{|l|}
4.79 \\
\end{tabular} & \pm 1.91 & 4.75 & $0.173^{\mathrm{m}}$ \\
\hline & Lymphocyte & 3.78 & \pm 1.35 & 3.90 & 4.08 & \pm 1.61 & 3.50 & $0.835 \mathrm{~m}$ \\
\hline & NLR & 1.71 & \pm 0.98 & 1.45 & 1.36 & \pm 0.71 & 1.45 & $0.285^{\mathrm{m}}$ \\
\hline & MPV & 6.42 & \pm 1.04 & 6.40 & 6.40 & \pm 0.96 & 6.30 & $0.867^{\mathrm{m}}$ \\
\hline \multirow[t]{4}{*}{ Grade IV-V } & Neutrophil & & \pm 2.08 & 4.90 & 4.18 & \pm 1.79 & 3.95 & $0.020^{\mathrm{m}}$ \\
\hline & Lymphocyte & 3.82 & \pm 1.18 & 3.60 & 4.91 & \pm 1.79 & 4.50 & $0.016^{\mathrm{m}}$ \\
\hline & NLR & 1.57 & \pm 0.89 & 1.31 & 0.96 & \pm 0.52 & 0.83 & $0.001^{\mathrm{m}}$ \\
\hline & MPV & 6.26 & \pm 0.84 & 6.10 & 6.48 & \pm 1.13 & 6.25 & $0.652 \mathrm{~m}$ \\
\hline
\end{tabular}

Neutrophil count, lymphocyte count and NLR did not differ significantly ( $p>0.05)$ between scar-positive and scarnegative patients with moderate (grade III) VUR (Table 4). The lymphocyte count was significantly higher $(\mathrm{p}<0.05)$ and the neutrophil count and NLR were significantly lower $(\mathrm{p}<0.05)$ in scar-positive patients with high-grade (grades IV-V) VUR than in scar-negative patients (Table 4).

\section{Discussion}

VUR increases the risk of renal scarring by establishing a ground for UTI and pyelonephritis. If the necessary precautions are not taken and the condition is not treated in a timely manner, VUR causes reflux nephropathy and CRF develops in 25\%-60\% of these patients (15). The reflux of the infected urine back to the kidney does not always cause parenchymal damage and renal scar in VUR (16). It has been shown that the inflammatory process is more influential than the direct damage caused by bacterial infection in renal scar development after pyelonephritis $(17,18)$. It has been suggested that even if the infection is treated and VUR is corrected, the inflammatory process that has already started continues and therefore scar may develop $(1,15)$. Partial benefits of the use of corticosteroids com- bined with antibiotic therapy have been observed in animal studies based on the hypothesis that the development of renal scarring can be reduced by preventing the inflammatory process (19). In a recent double-blind, placebo-controlled study conducted by Shaikh et al., patients who were treated for UTI were divided into two groups. One group received antibiotics and placebo, while the other group received antibiotics and corticosteroids. The development of the renal scar was found to be lower in the group in which corticosteroids were added to the treatment although the difference was not statistically significant (20). Based on the results of the study, it was argued that better results could be achieved by adding corticosteroids to the treatment of patients predicted to develop pyelonephritis and renal scarring. Urinary inflammatory biomarkers such as TGF- $\beta 1$, VEGF, and MCP-1 (15), Interleukin-18 (IL-18) are known to play a role in renal ischemia-reperfusion and acute kidney injury, and procalcitonin (PCT) and CRP serum inflammation markers have proven to be reliable in VUR patients (21). However, an easy-to-reach biomarker predicting renal scar is still not available.

The NLR is a simple, useful parameter that is used as a systemic inflammation marker. It has been widely employed to predict the outcomes of oncological, cardiovascular, gastrointestinal and hematogenous infections (22). It has been proposed as a marker of infection in patients with sepsis and has been reported to be associated with the severity of the disease (23). In the study performed by Terradas et al., increased mortality was demonstrated in patients with bacteraemia who had an NLR of $>7$ (24). In another study, it has been reported that the risk of sepsis increased after percutaneous nephrolithotomy in patients with an NLR of $\geq 2.5$ (25).

Based on the data from literature, we hypothesised that there might be a relationship between renal scarring and complete blood count parameters. Hence, we analysed the complete blood count parameters of patients diagnosed with VUR. The NLR was $0.99(1.16 \pm 0.7)$ in the group with renal scarring and $1.38(1.59 \pm 0.83)$ in the

Figure 1.

The relationship between NLR and renal scarring.

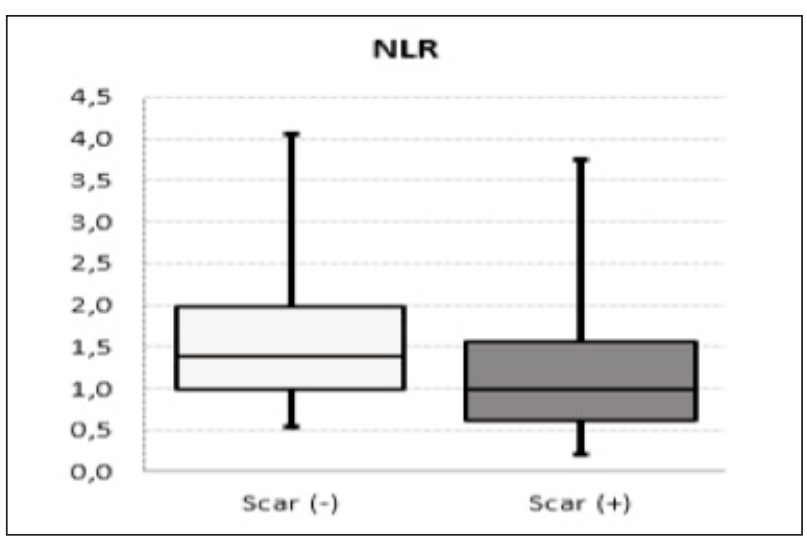


Figure 2.

Relationship between the grade of VUR and NLR.

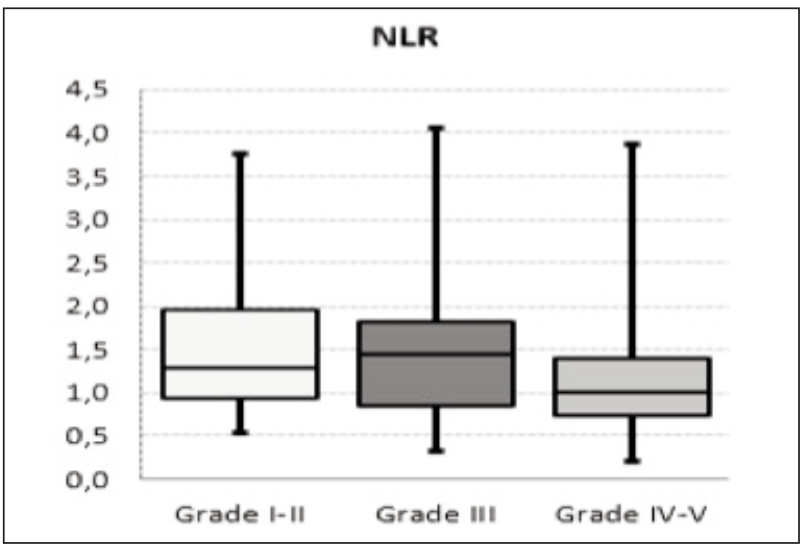

Figure 3.

The relationship between the grade of reflux and renal scarring.

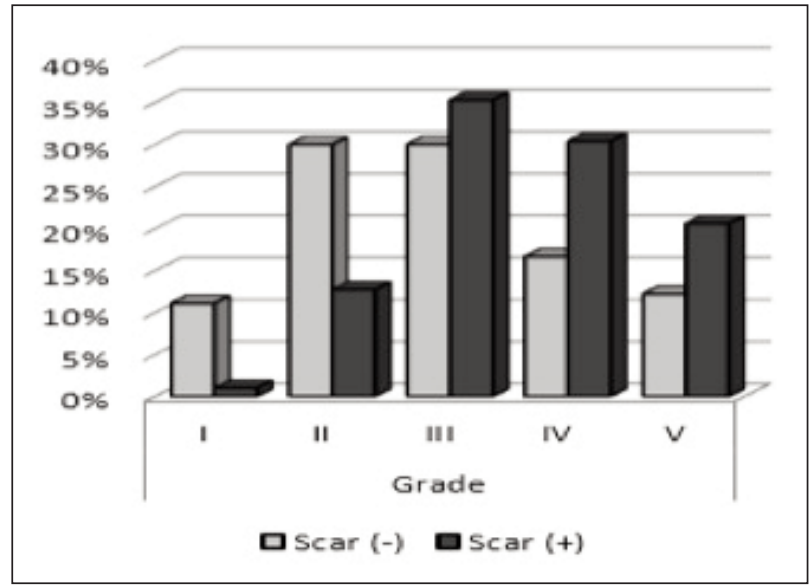

group without renal scarring. We found that NLR was low in patients with renal scars (Figure 1), and a relationship was discerned between the grade of reflux and NLR (Figure 2). Therefore, we considered that NLR can be used to predict renal scarring.

Risk factors precipitating the development of renal scarring have been identified in patients with VUR (26). One of these factors is the severity of the reflux. The risk of renal scar developing after pyelonephritis increases with the severity of VUR $(27,28)$. In a study involving 303 children with UTI who were under 2 years of age, Stokland et al. showed that the risk of renal scarring was elevated in Tc-99m DMSA scintigraphy in cases with high-grade VUR (29). In the carried out by Bandari et al., the rates of renal scarring were 33\%, 33\%, 40\%, 50\% and $80 \%$ in patients with grade I, II, III, IV and V VUR, respectively (30). Similarly, Jaukovic et al. found renal scars in $26 \%$ of the children with low-grade VUR and in $56 \%$ of the children with high-grade VUR (31).

In our study, the renal scar rates were 9\%, 32.5\%, $57.1 \%$, $67.3 \%$ and $65.6 \%$ in patients with grade I, II, III, IV and V VUR, respectively. As seen in VUR studies in the literature and in the present study, the rate of scarring increased as the grade of reflux increased (Figure 3). However, not all patients with high-grade reflux develop renal scarring and those with low-grade reflux can also develop renal scars since the inflammatory process and immune response progress differently in each patient $(17,32)$. In the subdata analysis of our study, the lymphocyte count was significantly higher $(\mathrm{p}<0.05)$ and the neutrophil count and NLR were significantly lower $(p<0.05)$ in patients with renal scarring who had high-grade (grades IV-V) reflux than in those without renal scarring. We identified a relationship between renal scarring and NLR in patients with high-grade (grades IV-V) VUR. Although our study did not establish this relationship in the low and moderate (grades I, II and III) reflux groups, we think that NLR could be the reason why some patients develop renal scarring while others with a similar grade of VUR do not.

Currently, requesting DMSA scintigraphy and performing VCUG for those with DMSA uptake are recommended as a Top-Down approach in the first-line workup after febrile UTI (13). VUR occurs in 24\%-39\% of patients with acute pyelonephritis detected by DMSA scintigraphy (33).

In a systematic review by Shaikh et al., DMSA changes were found in the acute phase in $57 \%$ of the patients after the first UTI episode and these changes were observed in 15\% of the patients during follow-up (32). Therefore, repeat DMSA imaging 6-12 months later is recommended to determine the long-term outcomes in patients with signs of acute pyelonephritis (34). However, DMSA screening in children is impractical and expensive (20). In addition, DMSA between the ages of 1-3 has disadvantages such as the need for sedation during scintigraphy (35) and irradiation (36). Therefore, we think that NLR can be used as a parameter in predicting renal scarring and that DMSA scintigraphy can reduce the number of shots.

\section{Limitations}

Our study has some limitations. The first limitation is the retrospective study design. Since the number of febrile UTI episodes in the study patients and whether they received an effective therapy are unknown, these data were not included in the study. Similarly, because we are a tertiary health centre, patients are referred from external centres. Therefore, most of the patients do not have complete blood count data for the acute period.

Therefore, infection parameters pertaining to the acute infection period were not included in the study. We think that the relationship between the complete blood parameters at the time of acute infection and renal scar formation should be examined with prospective studies.

\section{Conclusions}

We opine that NLR can be used as a parameter to predict renal scarring in patients with VUR and may even be a guiding marker candidate for treatment selection. In addition, we anticipate that the number of DMSA scans, which are costly and relatively difficult to implement, can be reduced in this manner. However, these findings need to be confirmed by well-designed prospective studies.

\section{REFERENCES}

1. Tekgül S, Riedmiller H, Hoebeke P, et al. European Association of Urology. EAU guidelines on vesicoureteral reflux in children. Eur Urol. 2012; 62:534-42. 
2. Sirin A, Emre S, Alpay H, et al. Etiology of chronic renal failure in Turkish children. Pediatr Nephrol. 1995; 9:549-52.

3. Chertin B, Abu Arafeh W, Kocherov S. Endoscopic correction of complex cases of vesicoureteral reflux utilizing Vantris as a new nonbiodegradable tissue-augmenting substance. Pediatr Surg Int. 2014; 30:445-8

4. Anders HJ, Ryu M. Renal microenvironments and macrophage phenotypes determine progression or resolution of renal inflammation and fibrosis. Kidney Int. 2011; 80:915-925.

5. Nikolic-Paterson DJ. CD4+ T cells: a potential player in renal fibrosis. Kidney Int. 2010; 78:333-5.

6. Cendron M. Reflux nephropathy. J Pediatr Urol. 2008; 4:414-21.

7. Jahnukainen T, Chen M, Celsi G. Mechanisms of renal damage owing to infection. Pediatr Nephrol. 2005; 20:1043-53.

8. Kapci M, Turkdogan KA, Duman A, et al. Biomarkers in the diagnosis of acute appendicitis. J Clin Exp Invest. 2014; 5:250-255

9. Turkmen K, Erdur FM, Ozcicek F, et al. Platelet-to-lymphocyte ratio better predicts inflammation than neutrophil-to-lymphocyte ratio in end-stage renal disease patients. Hemodial Int. 2013; 17:391-6.

10. Mantovani A, Cassatella MA, Costantini C, Jaillon S. Neutrophils in the activation and regulation of innate and adaptive immunity. Nat Rev Immunol. 2011; 11:519-31.

11. Bath P, Algert C, Chapman N, Neal B. PROGRESS Collaborative Group. Association of mean platelet volume with risk of stroke among 3134 individuals with history of cerebrovascular disease. Stroke. 2004; 35:622-6.

12. Hains DS, Cohen HL, McCarville MB, et al. Elucidation of renal scars in children with vesicoureteral reflux using contrast-enhanced ultrasound: a pilot study. Kidney Int Rep. 2017; 2:420-4.

13. Blumenthal I. Vesicoureteric reflux and urinary tract infection in children. Postgrad Med J. 2006; 82:31-5.

14. Duckett JW, Bellinger MF. A plea for standardized grading of vesicoureteral reflux. Eur Urol. 1982; 8:74-7.

15. Morozova O, Morozov D, Pervouchine D, et al. Urinary biomarkers of latent inflammation and fibrosis in children with vesicoureteral reflux. Int Urol Nephrol. 2020; 52:603-610.

16. Gordon I, Barkovics M, Pindoria S, et al. Primary vesicoureteric reflux as a predictor of renal damage in children hospitalized with urinary tract infection: a systematic review and meta-analysis. J Am Soc Nephrol. 2003; 14:739-44.

17. Bille J, Glauser MP. Protection against chronic pyelonephritis in rats by suppression of acute suppuration: effect of colchicine and neutropenia. J Infect Dis. 1982; 146:220-6.

18. Roberts JA, Roth JK Jr, Domingue G, et al. Immunology of pyelonephritis in the primate model. V. Effect of superoxide dismutase. J Urol. 1982; 128:1394-400.

19. Haraoka M, Matsumoto T, Takahashi K, et al. Suppression of renal scarring by prednisolone combined with ciprofloxacin in ascending pyelonephritis in rats. J Urol. 1994; 151:1078-80.

20. Shaikh N, Shope TR, Hoberman A, et al. Corticosteroids to prevent kidney scarring in children with a febrile urinary tract infection: a randomized trial. Pediatr Nephrol. 2020; 35:2113-2120.

21. Yavuz S, Anarat A, Bayazit AK. Interleukin-18, CRP and procalcitonin levels in vesicoureteral reflux and reflux nephropathy. Ren Fail. 2013; 35:1319-22.

22. Bolat D, Topcu YK, Aydogdu O, et al. Neutrophil to Lymphocyte Ratio as a predictor of early penile prosthesis implant infection. Int Urol Nephrol. 2017; 49:947-953.

23. Zahorec R. Ratio of neutrophil to lymphocyte counts--rapid and simple parameter of systemic inflammation and stress in critically ill. Bratisl Lek Listy. 2001; 102:5-14.

24. Terradas R, Grau S, Blanch J, et al. Eosinophil count and neutrophil-lymphocyte count ratio as prognostic markers in patients with bacteremia: a retrospective cohort study. PLoS One. 2012; $7: e 42860$

25. Sen V, Bozkurt IH, Aydogdu O, et al. Significance of preoperative neutrophil-lymphocyte count ratio on predicting postoperative sepsis after percutaneous nephrolithotomy. Kaohsiung J Med Sci. 2016; 32:507-513.

26. Lee YJ, Lee JH, Park YS. Risk factors for renal scar formation in infants with first episode of acute pyelonephritis: a prospective clinical study. J Urol. 2012; 187:1032-6.

27. Goldman M, Bistritzer T, Horne T, et al. The etiology of renal scars in infants with pyelonephritis and vesicoureteral reflux. Pediatr Nephrol. 2000; 14:385-8.

28. Zaffanello $M$, Cataldi L, Brugnara $M$, et al. Hidden high-grade vesicoureteral reflux is the main risk factor for chronic renal damage in children under the age of two years with first urinary tract infection. Scand J Urol Nephrol. 2009; 43:494-500.

29. Stokland E, Hellström M, Jacobsson B, et al. Renal damage one year after first urinary tract infection: role of dimercaptosuccinic acid scintigraphy. J Pediatr. 1996; 129:815-20.

30. Bandari B, Sindgikar SP, Kumar SS, et al. Renal scarring following urinary tract infections in children. Sudan J Paediatr. 2019; 19:25-30

31. Jaukovic L, Ajdinovic B, Dopudja M, Krstic Z. Renal scintigraphy in children with vesicoureteral reflux. Indian J Pediatr. 2009; 76:1023-6.

32. Shaikh N, Ewing AL, Bhatnagar S, Hoberman A. Risk of renal scarring in children with a first urinary tract infection: a systematic review. Pediatrics. 2010; 126:1084-91.

33. Levtchenko E, Lahy C, Levy J, et al. Treatment of children with acute pyelonephritis: a prospective randomized study. Pediatr Nephrol. 2001; 16:878-84.

34. Biassoni L, Chippington S. Imaging in urinary tract infections: current strategies and new trends. Semin Nucl Med. 2008; 38:56-66.

35. Gordon I. Issues surrounding preparation, information and handling the child and parent in nuclear medicine. J Nucl Med. 1998; 39:490-4.

36. Smith T, Gordon I, Kelly JP. Comparison of radiation dose from intravenous urography and 99Tcm DMSA scintigraphy in children. Br J Radiol. 1998; 71:314-9.

\section{Correspondence}

Mehmet Demir, MD (Corresponding Author) drdemir02@gmail.com

Ismail Yagmur, MD

dr_iyagmur@hotmail.com

Eyyup Sabri Pelit, MD

dreyyupsabri@hotmail.com

Bülent Katı, MD

bulentkati@yahoo.com

Eser Ördek, MD

dr_eseser@hotmail.com

Halil Çiftçi, MD

halilciftci63@hotmail.com

Harran University. Faculty of Medicine Urology Department

Sanliurfa (Turkey) 